\title{
Damage assessment and refurbishment of steam turbine blade/rotor attachment holes
}

\section{Hattingh, DG}

http://hdl.handle.net/10026.1/4316

\subsection{6/j.tafmec.2015.11.001 \\ THEORETICAL AND APPLIED FRACTURE MECHANICS}

All content in PEARL is protected by copyright law. Author manuscripts are made available in accordance with publisher policies. Please cite only the published version using the details provided on the item record or document. In the absence of an open licence (e.g. Creative Commons), permissions for further reuse of content should be sought from the publisher or author. 
Damage Assessment and Refurbishment of Steam Turbine Blade/Rotor Attachment Holes

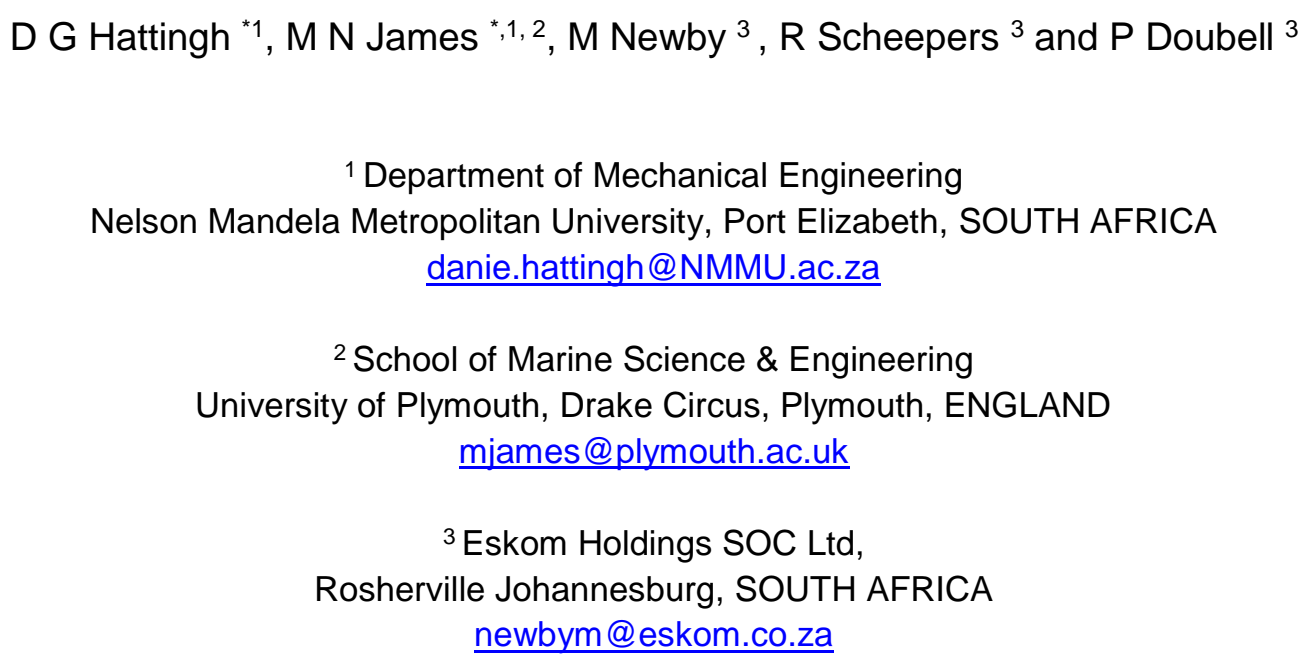

\begin{abstract}
This paper presents a case study dealing with the assessment of cracking observed at steam turbine blade attachment holes, and subsequent use of an innovative repair solution based on a friction processing technique, friction hydro-pillar processing (FHPP). This was performed with a bespoke welding platform developed specifically for repair of radially cracked or incorrectly drilled blade attachment holes in LP turbine rotors. The paper initially outlines a fracture mechanics analysis of observed in-service cracking aimed at assessing critical defect sizes to support repair or replacement scenarios. It then briefly discusses development of the FHPP process before focusing on characterisation of the residual stresses resulting from the welding process and their amelioration by heat treatment; a necessary part of the procedure approval for turbine refurbishment.
\end{abstract}

Keywords: friction hydro-pillar processing; crack assessment; residual stress; steam turbine; rotor blade repair

${ }^{*}$ Corresponding authors 


\section{Nomenclature:}

$\begin{array}{llll}\text { FHPP } & : & \text { Friction hydro-pillar processing } \\ \text { HAZ } & : & \text { Heat-affected zone } \\ \text { LP } & : & \text { Low pressure } \\ \text { PWHT } & : & \text { Post-weld heat treatment } \\ \text { TMAZ } & : & \text { Thermo-mechanically affected zone } \\ \text { SCC } & : & \text { Stress corrosion cracking } \\ \text { NDT } & : & \text { Non-destructive testing } \\ \text { MT } & : & \text { Magnetic particle testing } \\ \text { PAUT } & : & \text { Phased array ultrasonic testing } \\ \text { FEA } & : & \text { Finite element analysis } \\ \text { FAD } & : & \text { Fracture assessment diagram } \\ \text { rpm } & : & \text { Revolutions per minute } \\ \mathrm{S}_{\mathrm{r}} & : & \text { Load ratio in the FAD } \\ \mathrm{K}_{\mathrm{r}} & : & \text { Fracture ratio in the FAD } \\ \mathrm{R}_{\mathrm{e}} & : & \text { Yield strength } \\ \mathrm{R}_{\mathrm{m}} & : & \text { Tensile strength } \\ & & \end{array}$

\section{Introduction}

Turbine failures cost power generation utilities more than one billion dollars per annum [1] and arise primarily from problems with blades and rotor discs. Significant attention has therefore been directed over many years to identifying turbine steam path damage mechanisms [1], evaluating the design of turbine components and their operating environments, e.g. [2, 3] and with repair and retrofit upgrade strategies for discs and blades $[4,5]$. The present paper is concerned with the development of an innovative friction weld processing technique in support of cost-effective repair of cracking experienced at the attachment holes of finger-pinned steam turbine blades. 
As noted by McCloskey [1], there are strong economic pressures world-wide to move towards longer intervals between major turbine inspection outages, backed up by risk and decision analysis based on a quantitative, probabilistic approach to life assessment and condition monitoring, e.g. [6]. Repair or retrofitting of turbines to extend the life of existing plant is therefore an attractive option for owners of mature steam turbine plant [4]. Mund [4] further notes that about a third of the installed steam generating capacity is older than 30 years, making major overhauls and refits inevitable components of life extension.

Failures associated with turbine blades and their attachment points are the single largest cause of decreased power plant availability [7]. Despite very significant attention to LP turbine blade design evaluation, e.g. [2], the complex interaction between operating conditions, blade natural frequencies, dynamic blade response and vibrational stresses can, however, still cause blade and rotor disc cracking problems after a relatively small number of operating hours $[3,5]$. Root cause analysis generally identifies the cracking as due to either stress corrosion [8] or to fatigue from blade resonance problems [5], although there are reported cases of blade failure that have been ascribed to manufacturing problems, e.g. grain boundary carbide depletion in a martensitic stainless steel [9]. There are strong drivers to repair blades and rotors, as this is often both feasible and economically advantageous.

When such cracking is detected, it is usually the case that fracture mechanics is used to assess critical defect size and residual life, as an aid to evaluating the various repair/replace/run scenarios and the scheduling of outages to enable such refurbishment work to occur. Blade replacement is the conventional approach to remedial work, but welding offers significant advantages in terms of decreasing the duration of turbine outages and is hence is an economical solution for refurbishment work on blades [10]. Development of a repair welding strategy involves selection of a process, process parameters and welding consumables, and optimisation of post-weld heat treatment (PWHT) to achieve an optimised combination of residual stress and microstructure (which governs toughness and tensile strength). In this respect, there have been reported instances of blade failures where incorrect welding procedures were identified as responsible for the failure [11]. 
Gas tungsten arc [10] and laser welding [12] have been used to repair steam turbine blades, but solid-state friction stir processing techniques can be considerably more costeffective than either conventional fusion welding or replacement, in application to the repair of cracking at, or misaligned drilling of, attachment holes for finger-pinned turbine blades. In particular, the lower peak temperatures associated with friction stir techniques lead to generally lower values of the weld-induced residual stresses, and to lower defect populations in the weld zone.

The present paper discusses a fracture mechanics analysis of stress corrosion cracking (SCC) detected in the central blade attachment prong of a stage 1 LP turbine disc in a 200 MW unit, and their repair using an innovative friction processing technique, friction hydropillar processing, FHPP $[13,14]$. FHPP was performed using a bespoke welding platform developed specifically for repair of radially cracked or incorrectly drilled blade attachment holes (see the process schematic in Figure 1) in 3.5NiCrMoV (Grade 26NiCrMoV14-5) steel [14] used for LP turbine rotors. Issues covered in this paper include fracture mechanics assessment of the acceptability of cracks (to determine whether immediate repair/replacement was necessary or whether the unit could continue to operate until a scheduled outage), and the development of the friction welding platform, before focusing on a key issue for life assessment in power plant; i.e. characterising the residual stresses resulting from the welding process, their amelioration by heat treatment and the resulting microstructure and hardness.

Residual stresses were measured using neutron diffraction strain scanning of test specimens machined from ex-service rotors, processed to simulate various stages in the repair process, i.e. as-welded and undrilled, as-welded and subsequently drilled for the blade attachment pin, undrilled and post-weld heat treated (PWHT), drilled and PWHT. The neutron diffraction measurements were made on the SALSA instrument at the Institut LaueLangevin (ILL), Grenoble through beam-time awarded under experiment 1-02-83. 


\subsection{Turbine rotor-blade attachment hole problems}

The South African power generation utility, Eskom, has experienced occasional instances of misaligned drilling, attachment hole ovality and fatigue or stress corrosion cracking at finger blade attachment holes on LP turbine rotors. The particular rotors under consideration have three attachment fingers and magnetic particle inspection is used to identify initial defect indications in-situ, with further investigation utilising ultrasonic or eddy current inspection with the blades removed. Condition monitoring of these rotors can be difficult if cracks exist at the hole in the central finger, even when the blade is removed. Where such defects have been detected, their influence on blade dynamic response and life is typically assessed using $3 \mathrm{D}$ finite element modelling to determine the stresses in each of the six attachment holes (two on each prong) seen in Figure 1. This can be combined with a fracture mechanics analysis to obtain values of stress intensity factor under various operating conditions as a function of crack size and position. This type of analysis allows the operator to decide whether immediate repair or replacement of the disc (or blades) is necessary, and to schedule remedial work and set inspection intervals if the rotor can continue in operation.

In the case study presented here the decision was made to repair the attachment holes and Figure 2 shows the type of defects which can be repaired by welding and that are well suited to use of the friction hydro-pillar processing (FHPP) technique.

\section{Fracture Mechanics Analysis}

Stress corrosion cracking (SCC) especially of shrunk-on discs is a well-known damage mechanism in power generation steam turbines. Areas that are typically affected include the disc bore, hub web and the blade root fixing areas. Non-destructive testing (NDT) techniques, including magnetic particle testing (MT) and phased array ultrasonic testing (PAUT) can be successfully applied to the first two areas to detect and size SCC cracks. Surface treatment measures such as roller burnishing and shot peening can be implemented 
to improve the SCC resistance of these areas, while remedial work may include excavation and/or weld repair. However, for the disc rim or blade root fixing area, viable NDT and surface treatment techniques are limited, especially in the case of pinned finger root designs where access is restricted. Inspection of the inner prong, which carries the highest steady load, is not possible without removal of the blades. This is a costly and time consuming activity which is rarely done except when blade replacement or repair are required. Removal of blades has an associated risk of damage to the disc pinholes which may then require repair. Moreover, pinhole reaming required for blade re-installation enlarges the pinhole diameter and can only be done a limited number of times before the pinhole size limit is reached (for disc and/or blade). One conventional solution is to bush the pinhole thereby removing the damage or SCC crack. However, this technique has limits both on bush diameter and the number of bushes that can be used on any one turbine blade row.

Whilst the preferred approach to any defects in turbine discs is to either repair or replace, a further option involving limited operation with defects/cracks present provides operational flexibility and the ability to optimise outage scheduling. For such cases it is imperative that structural integrity be demonstrated with appropriate factors of safety. The acceptability of SCC cracks detected in-service in the central prong (of three) on a stage 1 LP turbine disc in a $200 \mathrm{MW}$ unit was considered in this case study (Figure 3). A cyclic symmetric three dimensional finite element model of a segment of the disc with one blade was developed. Frictionless contact between the root pins and the disc holes was applied. In order to reduce solution times bonded contact between the pins and the blade was assumed. In addition to the 'as-designed' case models containing the detected crack as well as the postulated extended crack were also analysed. Quarter node elements were used to mesh the crack fronts in order to calculate the applied stress intensities. Hexahedral elements were used as far as possible except in more complex geometries where tetrahedral elements were used. The total number of elements for the 'as-designed' case was 13565 and for the 'cracked' case was 29328. Linear elastic material properties were applied in all cases with an elastic modulus of $205 \mathrm{GPa}$ and a Poison's ratio of 0.3 . A material density of $7850 \mathrm{~kg} / \mathrm{m}^{3}$ was used 
throughout. Finite element analysis (FEA) of the 'as-designed' case indicated that the $1^{\text {st }}$ principal stress for the disc rim is in the radial direction with peaks at the 2 - 3 o'clock and 9 10 o'clock positions on the bottom pinhole on the central prong (Figure 4). This was in good agreement with the initiation position and propagation direction (circumferential) observed on the cracked disc from MT testing.

The fracture mechanics analysis has two stages, with the first involved in assessing the possibility of brittle fracture under the assumed defect size for several operating scenarios, while the second considers the possibility of continued crack growth and aims to determine the duration of further safe operation. For a through-prong SCC crack at the 2 o'clock position with a length from the hole edge of $8 \mathrm{~mm}$, FEA calculations gave a value of the applied stress intensity factor for an operating speed of $3,000 \mathrm{rpm}$ to be $38 \mathrm{MPa} \sqrt{\mathrm{m}}$. The hypothetical worst case considered was an overspeed incident to $3,600 \mathrm{rpm}$ at room temperature. Here the applied stress intensity will reach $54 \mathrm{MPa} \sqrt{\mathrm{m}}$ which is still well below the room temperature toughness of the material (expected to be in the order of $142 \mathrm{MPa} \sqrt{\mathrm{m}}$ ) and hence the fracture toughness analysis demonstrated the required defect tolerance to cracks of the detected size.

For continued operation, without addressing the SCC crack, the SCC propagation rate is expected to be in the order of $3 \mathrm{~mm} / 10,000$ hours of operation. FEA was used to calculate the increase in the applied stress intensity factor and reference stress with time, for a conservatively assumed initial through-prong crack length of $36 \mathrm{~mm}$, i.e. an initial crack spanning two pinholes and extending $3 \mathrm{~mm}$ on opposing sides of the two pinholes. Results were plotted on a Level 1 failure assessment diagram (FAD) in accordance with reference [15]. The FAD axes are load ratio $S_{r}$, defined as the value of the calculated reference stress divided by the flow strength, which is assumed to be the arithmetic mean of the yield strength and the tensile strength up to a maximum value of 1.2 times the yield strength, and the fracture ratio $K_{r}$ defined as the calculated value of applied stress intensity factor divided by the material toughness value. Figure 5 shows the FAD for the disc crack where crack growth has been plotted for three speeds from the normal 
operating condition of $3,000 \mathrm{rpm}$ to the worst case overspeed of $3,600 \mathrm{rpm}$. It shows that brittle fracture is not expected but that overload failure can occur in an overspeed situation after a further 18,500 hours (or just over two years) of operation (as shown in Figure 6).

This assessment indicated that significant cracking is tolerable for a period of time from an operational point of view, providing some flexibility for postponing repair. However, if cracks are allowed to propagate they will reach sizes which are no longer repairable. Hence disc hole repair was scheduled for a suitable outage period.

\section{The FHPP Process}

Friction hydro-pillar processing is a variant of the friction stir welding process developed at TWI in 1991. FHPP involves rotating a consumable tool concentrically in a hole whilst applying a downwards load, to continuously generate a localised plasticised layer. The plasticised material develops at a rate faster than the axial feed rate of the consumable tool, and hence the plasticised rubbing surface rises up around the length of the tool giving a dynamically recrystallised interface layer which forms the weld. There are only a few reports of the use of FHHP in the literature, although Xu et al [16] have provided a useful numerical simulation aimed at determining optimised hole/stud geometries. In the application of FHPP as a potential repair technique for cracks or incorrectly drilled holes in LP turbine rotors, the process consists of six stages that are illustrated in Figure 7:

1. A backing plate is introduced and used to support the blade attachment finger;

2. The damaged region around the hole is machined out using the specially designed FHPP platform;

3. FHPP is used to repair the hole, in a process integrated with the removal of the damaged region;

4. Post-weld heat treatment (PWHT) is used to relax residual stresses;

5. Excess weld metal is removed by machining; 
6. The blade attachment hole is accurately re-drilled.

Inclusion of this procedure amongst the range of welding processes used in the power generation industry requires the development of a weld qualification procedure and record. This necessitates an evaluation of the microstructure, mechanical properties, residual stresses and susceptibility to stress corrosion cracking (SCC) of the weld repair. The residual stress, hardness and microstructural aspects form the body of this paper.

The weld trial specimens used in the residual stress work comprised three individual parts; a consumable backing plate, a steel block simulating a rotor finger and a consumable tool. These parts were manufactured from 26 NiCrMoV14-5 steel alloy obtained from an exservice rotor. This is a structural forging steel using to manufacture low pressure steam turbine components with the composition and mechanical properties shown in Table 1 , where $R_{e}$ is the yield strength and $R_{m}$ the tensile strength.

Typical microstructures in the as-forged rotor comprise a mixture predominantly of tempered bainite and some tempered martensite; although small amounts of retained austenite are also present (see Figure 8). The work reported in this paper used 5 specimens intended to simulate the various stages in applying the FHPP process to repair of damaged blade attachment holes in a rotor. Figure 9 illustrates the steel test piece (size $95 \times 95 \times 18$ $\mathrm{mm}$ ) used to simulate the repair process. A thickness of $18 \mathrm{~mm}$ was chosen to be representative of the upper limit of finger thickness found in actual turbine discs.

FHPP parameters are given in Table 2; the hole diameter in the specimen was 14.8 $\mathrm{mm}$ and the diameter of the stud used to fill the hole by FHPP was $14.0 \mathrm{~mm}$. Both the magnitude and duration of application of the forging force are given in Table 2. The upset forging distance consolidates the FHPP weld through increasing filler metal diameter by compressing plasticised tool material into the weld under the forging force. Reference [14] describes the work performed to determine the optimum welding process parameters. As described below, certain specimens were post-weld heat treated (PWHT) at $680^{\circ} \mathrm{C}$ for 1 hour and then furnace cooled. The temperature of $680^{\circ} \mathrm{C}$ is below the $A_{c 1}$ temperature for this steel $\left(725^{\circ} \mathrm{C} ; \mathrm{A}_{\mathrm{c} 1}\right.$ is the austenite transformation start temperature on heating the steel) 
and hence the intention was to achieve stress-relaxation by reducing the yield strength of the material to the level of acceptable residual stress.

\section{Microstructure and Hardness}

FHPP leads to relatively complex macrostructures as shown in Figure 10 for the W2 (aswelded, undrilled) specimen that shows approximately half of the FHPP weld zone. The flow lines are indicative of the mixed forging and rotation nature of the process and Figures 11 and 12 give typical micrographs of the HAZ and tool core regions in W2 (as-welded) while Figure 13 demonstrates that PWHT produces a microstructure similar to that observed in the parent plate and hence the microhardness values would also be expected to be similar. Microstructures appear to be very similar in the two Cartesian coordinate directions in which hardness and residual stress measurements were made ( $z$ and $x$ - see Figure 14). Measurements were made in these two directions at three depths below the top surface -3 $\mathrm{mm}, 9 \mathrm{~mm}$ (mid-depth) and $15 \mathrm{~mm}$. Figure 15 shows mid-depth Vickers hardness data in both coordinate directions for all specimens measured under a $500 \mathrm{gf}$ load. Only slight differences are apparent in the hardness values between the two directions or between the two as-welded (W2 and W3) or the two PWHT (W4 and W5) specimens. As would be expected the as-welded specimens (W2 and W3) show a much higher hardness value (by some $200 \mathrm{HV}_{\mathrm{V}}$ ) than those that were subject to PWHT (W4 and W5). These high values extend out to the edge of the TMAZ at around $10 \mathrm{~mm}$ from the centreline of the specimens, when hardness values drop sharply to those representative of the parent steel $(\approx 280-300$ $\mathrm{H}_{\mathrm{v}}$ ). Hardness values in W4 and W5 remain fairly constant at around $300 \mathrm{H}_{\mathrm{v}}$ in the $x$ direction and drop slightly from the weld zone to the parent steel in the $z$-direction.

In specimens W4 and W5 that were subject to PWHT the hardness curves at all three depths $(3 \mathrm{~mm}, 9 \mathrm{~mm}$ and $15 \mathrm{~mm})$ were almost identical, while small systematic variations were apparent in the as-welded specimens W2 and W3 (Figure 16). It is clear that in specimen W2 (Figure 16a) the hardness in the welded zone at $3 \mathrm{~mm}$ is lower, while the 
hardness decays more slowly outside the welded zone at the $15 \mathrm{~mm}$ depth, than observed at the other two depths. Figure $16 \mathrm{~b}$ shows that the extent of the high hardness zone in specimen W3 gets progressively slightly larger as the depth in the specimen increases from $3 \mathrm{~mm}$ to $15 \mathrm{~mm}$. These hardness variations as a function of depth are related to details of the thermomechanical forging process and the interaction with the backing plate, i.e. heat input across a larger region coupled with cooling at similar rates; however, exact mechanisms remain unclear.

\section{Residual Stress Measurements}

Residual stress values were calculated from strain measurements made in all three coordinate directions at selected points in the rotor samples. Neutron diffraction strain scanning measurements were made on the SALSA instrument at the ILL, Grenoble, with a

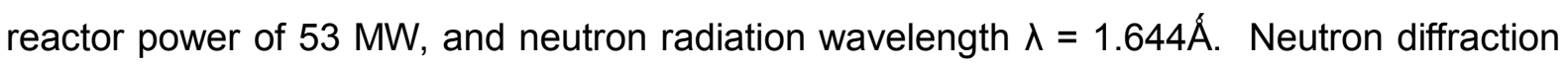
measurements of residual stress can be made in steel specimens up to around $30 \mathrm{~mm}$ thick with a spatial resolution of around $500 \mu \mathrm{m}$ and an accuracy of approximately $\pm 50 \mu \varepsilon$. In this work, in the worst case of the as-welded specimens, the errors in the strain measurements varied between $200 \mu \varepsilon$ in the weld zone to $20 \mu \varepsilon$ in the parent material. After heat treatment the errors in the weld zone reduced to approximately $65 \mu \varepsilon$, equivalent to an error stress in each of the three coordinate directions of approximately $29 \mathrm{MPa}$. Lattice spacing between atomic planes in the crystal structure is calculated using the Bragg equation (1):

$$
n \lambda=2 d \sin \theta
$$

In equation (1), $\lambda$ is the wavelength of the neutron radiation, $d$ is the spacing between layers of atoms, $\theta$ is the angle that the incident beam makes with the surface of the specimen and constructive interference occurs when $n$ has an integer value, i.e. the waves reflected from different atomic layers are perfectly in-phase with each other. 
Strain can be obtained from the ratio of strained to unstrained lattice spacing via knowledge of the unstrained lattice parameter $d_{0}$, which was measured using a comb specimen described in reference [17]. Single averaged values of $d_{0}$ were used for the parent plate, weld nugget and HAZ microstructures. The various specimens are described in Table 3, with the coordinate directions defined as shown in Figure 14, where the two directions in the surface plane of the specimens are $x$ and $z$ while $y$ was defined through the thickness of the plate (short transverse direction). Strain measurements were made in W2, W3, W4 and W5 in all three coordinate directions at the mid-depth $(y=9 \mathrm{~mm})$ of the attachment finger at a series of positions along the $x$-direction from the specimen centreline (see Table 4 for details). In addition, for W4 and W5, measurements in all three Cartesian coordinate directions were also made on lines at $y=3 \mathrm{~mm}$ and $y=15 \mathrm{~mm}$, where $y=0$ represents the top surface of the specimen.

Stresses were calculated from the strains using the generalised Hooke's law for 3D given below for the case of $\sigma_{x x}$ :

$$
\sigma_{x x}=\frac{E}{(1-2 v)(1+v)}\left[(1-v) \varepsilon_{x x}+v \varepsilon_{y y}+v \varepsilon_{z z}\right]
$$

The calculated residual stress values for all three coordinate directions are given in Figure 17 for the various measurement positions in the $x$-direction. The key coordinate directions for crack initiation and growth are $x$ and $z$ and the data show that the PWHT process is very effective in relaxing the substantial residual stress peaks in the weld zone. Reductions are achieved in the $x$-direction stress (Figure 17a) from peak values around -380 MPa near the HAZ boundary in specimens W2 and W3 to values below $100 \mathrm{MPa}$ at similar positions in specimens W4 and W5. In the case of the $z$-direction stresses (Figure 17b) the reduction is even more marked, from peak tensile values of circa $500 \mathrm{MPa}$ in W2 and W3 to values close to zero in W4 and W5. It is also apparent that drilling an $8 \mathrm{~mm}$ diameter hole in the as-welded specimen leads to a positive residual stress near the edge of the hole in the $x$ - 
direction (Figure 17a - W3). PWHT of a specimen with an $8 \mathrm{~mm}$ hole substantially decreases the magnitude of the residual stress at all positions (W4).

It is also interesting to compare the residual stress levels at the three different $y$-positions where measurements were made, i.e. $3 \mathrm{~mm}, 9 \mathrm{~mm}$ and $15 \mathrm{~mm}$ below the top surface of the specimen. Figure 18 shows this data for the $z$-coordinate direction in specimens W5 (undrilled PWHT) and W4 (drilled PWHT). In all cases, peak stress values in the $x$ and $z$ coordinate directions do not exceed approximately $100 \mathrm{MPa}$.

Figure 19 shows a comparison between hardness and $x$-coordinate direction stress at the mid-depth in W2 (as-welded) and W5 (undrilled PWHT). It shows that whilst in W2 there is a reasonable correlation between the extent of high hardness $(\approx 15 \mathrm{~mm})$ and the zone of high residual stress values, there is no direct comparison between the various peaks in hardness and residual stress. The zone of slightly elevated hardness values in W5 does not appear to be reflected in elevated residual stress values over the same region.

\section{Conclusions}

A FHPP technique has been developed for use with a bespoke welding platform that is suitable for cost-effective repair of disc/blade attachment hole cracking in-situ on a steam turbine rotor (Figure 20). The WeldCore ${ }^{\circledR}$ process has been registered and can also be used to extract samples for creep damage analysis. The case study presented in this paper relates to cracking experienced at the attachment holes of finger-pinned stage 1 LP steam turbine blades on a 200MW unit. Neutron diffraction residual strain scanning was performed at the ILL in Grenoble, France on test specimens machined from ex-service rotors, intended to simulate various stages in the repair process (see Figure 3); as-welded and undrilled (W20, as-welded and subsequently drilled for the blade attachment pin (W3), undrilled and PWHT (W5), drilled and PWHT (W4). PWHT has been shown to substantially reduce the peak magnitudes of the residual stress associated with the welding process, from peak tensile values of around $500 \mathrm{MPa}$ in in W2 and W3 to values close to zero in W4 and W5. Drilling an $8 \mathrm{~mm}$ hole in the as-welded specimen (W3), to simulate a new pin attachment 
hole, leads to a positive residual stress near the free surface in the $x$ and $y$-coordinate directions. PWHT of a specimen with an $8 \mathrm{~mm}$ hole substantially decreases the magnitude of the residual stress at all positions (W4). It is clear the FHPP provides a viable alternative to fusion welding for repair of radially cracked or incorrectly drilled blade attachment holes in LP turbine rotors.

\section{Acknowledgements}

The award of beamtime on the SALSA instrument at the ILL, Grenoble through experiment 1-02-83 and the support of the beamline scientist, Dr Thilo Pirling, are gratefully acknowledged. The significant assistance of W.G. Pentz and L.G. von Wielligh in development of the welding process and procedure is also gratefully acknowledged. Terry Richards provided invaluable assistance with microhardness measurement and microstructural preparation.

\section{References}

1. McCloskey, T.H. Troubleshooting Turbine Steam Path Damage Mechanisms. in Proceedings of the Thirty-First Turbomachinery Symposium 2002. College Station, TX.

2. Dewey, R.P. and A.V. Sarlashkar, Low-pressure turbine blade design evaluation. 1995, Electric Power Research Institute: Rochester, NY. p. 74.

3. Sanvito, M., et al., Analysis of LP steam turbine blade vibrations: experimental results and numerical simulations, in 10th International Conference on Vibrations in Rotating Machinery, ImechE, Editor. 2012, Woodhead Publishing. p. 189-197.

4. Mund, F.C., Steam turbine upgrades for power plant life management and performance improvement, in Power Plant Life Management and Performance Improvement, J.E. Oakey, Editor. 2011, Woodhead Publishing. p. 535-572.

5. $\mathrm{Xu}, \mathrm{Z} .-$ L., J.-P. Park, and S.-J. Ryu, Failure analysis and retrofit design of low pressure 1st stage blades for a steam turbine. Engineering Failure Analysis, 2007. 14(4): p. 694-701.

6. Chen, T.-L., Real-time turbine maintenance system. Expert Systems with Applications, 2009. 36(4): p. 8676-8681.

7. Dewey, R.P. and N.F. Rieger, Survey Steam Turbine Blade Failures. 1985, Electric Power Research Institute: Rochester, NY. p. 110.

8. Nalbandian, A. and A. Tipton, Root cause analysis stean turbine generator event. 2013: Cranston, RI. p. 102.

9. Saxena, S., et al., Coupled mechanical, metallurgical and FEM based failure investigation of steam turbine blade. Engineering Failure Analysis, 2015. 52: p. 35-44. 
10. Bhaduri, A.K., et al., Repair welding of cracked steam turbine blades using austenitic and martensitic stainless-steel consumables. Nuclear Engineering and Design, 2001. 206(2-3): p. 249-259.

11. Kubiak Sz, J., et al., Failure analysis of steam turbine last stage blade tenon and shroud. Engineering Failure Analysis, 2007. 14(8): p. 1476-1487.

12. Lin, C.-M., Parameter optimization of laser cladding process and resulting microstructure for the repair of tenon on steam turbine blade. Vacuum, 2015. 115: p. 117-123.

13. Hattingh, D.G., et al. Friction taper stud welding of creep resistant 10CrMo910. in Friction Stir Welding and Processing V, TMS 2009 Anual Meeting, 15-19 February 2009. 2009. San Francisco, CA: Wiley.

14. Hattingh, D.G., L.G. von Wielligh, and W.G. Pentz, Feasibility of utilising friction hydro pillar processing as a repair technique for incorrectly drilled holes, in African Fusion. 2013, Crown Publications: Johannesburg. p. 7.

15. Standards, B., BS 7910:2005 Guide to methods for assessing the acceptability of flaws in metallic structures. 2005, BSI.

16. $\mathrm{Xu}, \mathrm{Y} . \mathrm{C}$. , et al., Numerical simulation of the effects of various stud and hole configurations on friction hydro-pillar processing. International Journal of Mechanical Sciences, 2015. 90: p. 4452.

17. Hughes, D.J., et al., The Use of Combs for Evaluation of Strain-free References for Residual Strain Measurements by Neutron and Synchrotron X-ray Diffraction. Journal of Neutron Research, 2003. 11(4): p. 289-293. 
Table 1 Composition and properties of DIN 26NiCrMoV14-5.

\begin{tabular}{|c|c|c|c|c|c|c|c|c|c|c|}
\hline C & $\mathrm{Si}$ & $\mathrm{Mn}$ & S & $P$ & $\mathrm{Cr}$ & $\mathrm{Ni}$ & Mo & V & $\begin{array}{c}\mathrm{R}_{\mathrm{e}} \\
\mathrm{MPa}\end{array}$ & $\begin{array}{c}\mathrm{R}_{\mathrm{m}} \\
\mathrm{MPa}\end{array}$ \\
\hline 0.22 & $\leq 0.15$ & 0.15 & $\leq 0.007$ & $\leq 0.010$ & 1.20 & 3.40 & 0.25 & 0.05 & 800 & 950 \\
\hline 0.32 & & 0.40 & & & 1.80 & 4.00 & 0.45 & 0.15 & $\min$ & 1100 \\
\hline
\end{tabular}

Table 2 FHPP parameters used to manufacture test specimens.

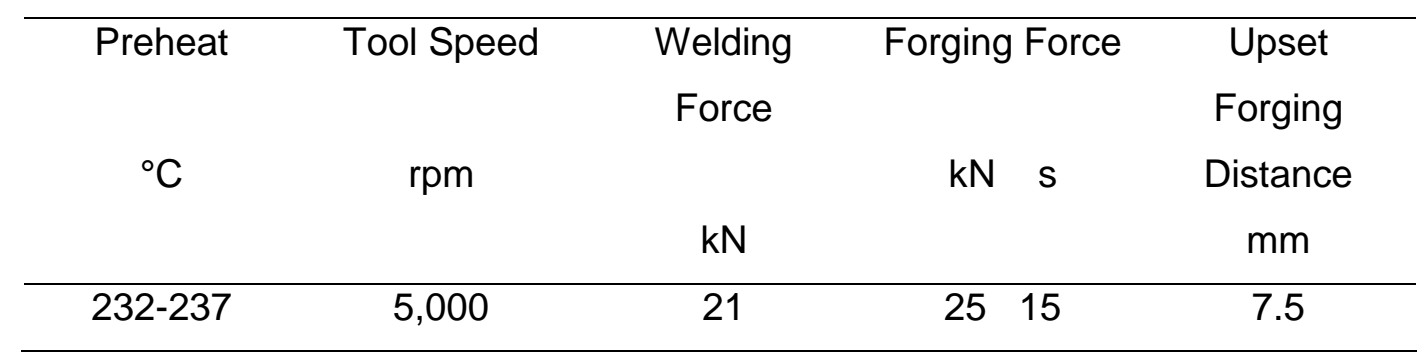

Table 3 Specimen description.

\begin{tabular}{cl}
\hline Identification & Condition \\
\hline W1 & As-welded used for $d_{0}$ measurements \\
W2 & As-welded, undrilled \\
W3 & As-welded, drilled with $8 \mathrm{~mm}$ hole \\
W4 & PWHT, drilled with $8 \mathrm{~mm}$ hole \\
W5 & PWHT \\
\hline
\end{tabular}


Table $4 \quad$ Strain scanning measurement spacing along the $x$-direction.

\begin{tabular}{cc}
\hline Specimens & Strain Measurement Positions \\
\hline W2 and W5 & $0,2,4.5,6,8,9,10,11,12,13.33,15,17.5,20,43$ \\
W3 and W4 & $--4.5,6,8,9,10,11,12,13.33,15,17.5,20,43$ \\
\hline
\end{tabular}




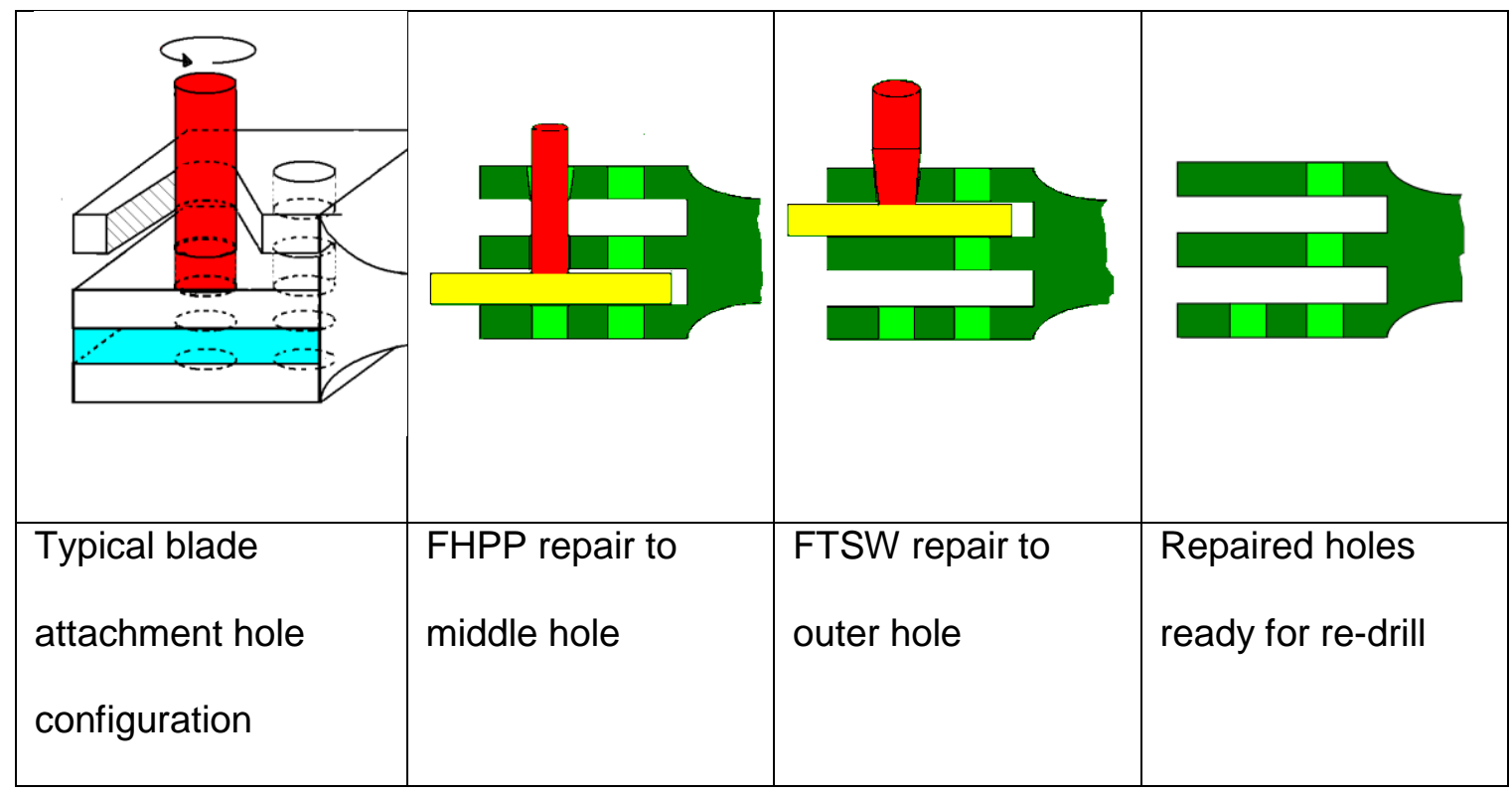

Figure 1 Schematic illustrating the repair of finger blade attachment points by FHHP.


Figure 2 Exemplars of a) attachment hole misalignment; b) hole ovality (marked with the arrow which identifies a slight gap between pin and hole in the centre attachment finger of the blade); c) radial cracking. 




Figure 3 Typical stage 1 steam turbine shrunk-on disc showing pinned finger root design with three prongs and two rows of pinholes (lower row indicated by arrow).

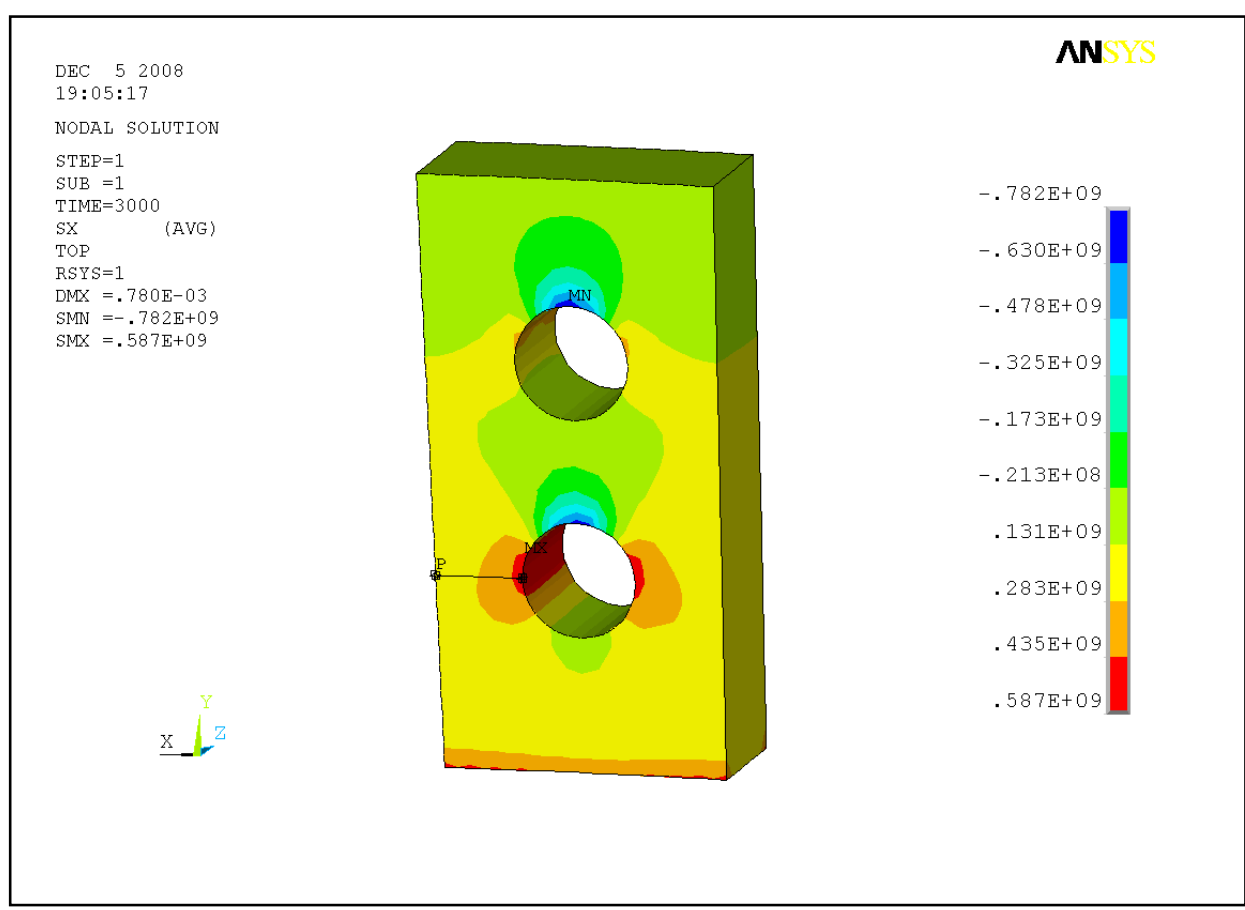

Figure 4 Radial stress distribution for the centre prong of a stage 1 steam turbine disc showing peak stress at the bottom pinhole. 




Figure 5 Failure Assessment Diagram (FAD) for SCC crack propagating from a $36 \mathrm{~mm}$ initial length.

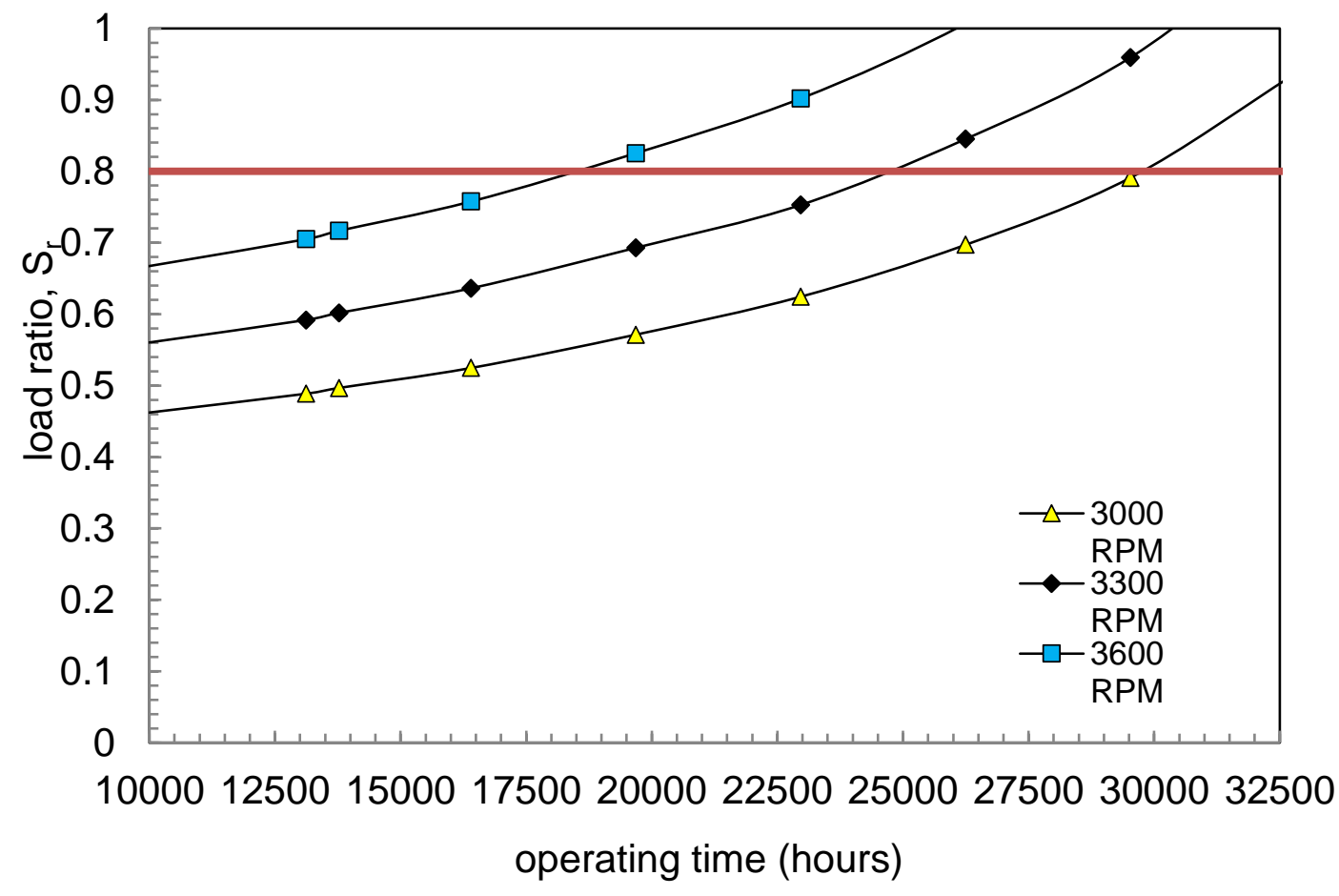

Figure 6 Failure by overload expected after 18,500 hours of operation (3,600 rpm load case). 


\begin{tabular}{|c|c|c|c|c|c|}
\hline $\begin{array}{c}\text { Damaged } \\
\text { hole in } \\
\text { component }\end{array}$ & $\begin{array}{c}\text { Introduction } \\
\text { of backing } \\
\text { plate }\end{array}$ & $\begin{array}{c}\text { Machining } \\
\text { of } \\
\text { damaged } \\
\text { hole }\end{array}$ & $\begin{array}{c}\text { FHPP and } \\
\text { PWHT }\end{array}$ & $\begin{array}{c}\text { Machining } \\
\text { of excess } \\
\text { material }\end{array}$ & $\begin{array}{c}\text { Drilling of } \\
\text { new hole }\end{array}$ \\
\hline & & & & & \\
\hline
\end{tabular}

Figure $7 \quad$ Stages in the FHPP repair of damaged blade attachment finger holes in a LP turbine rotor.

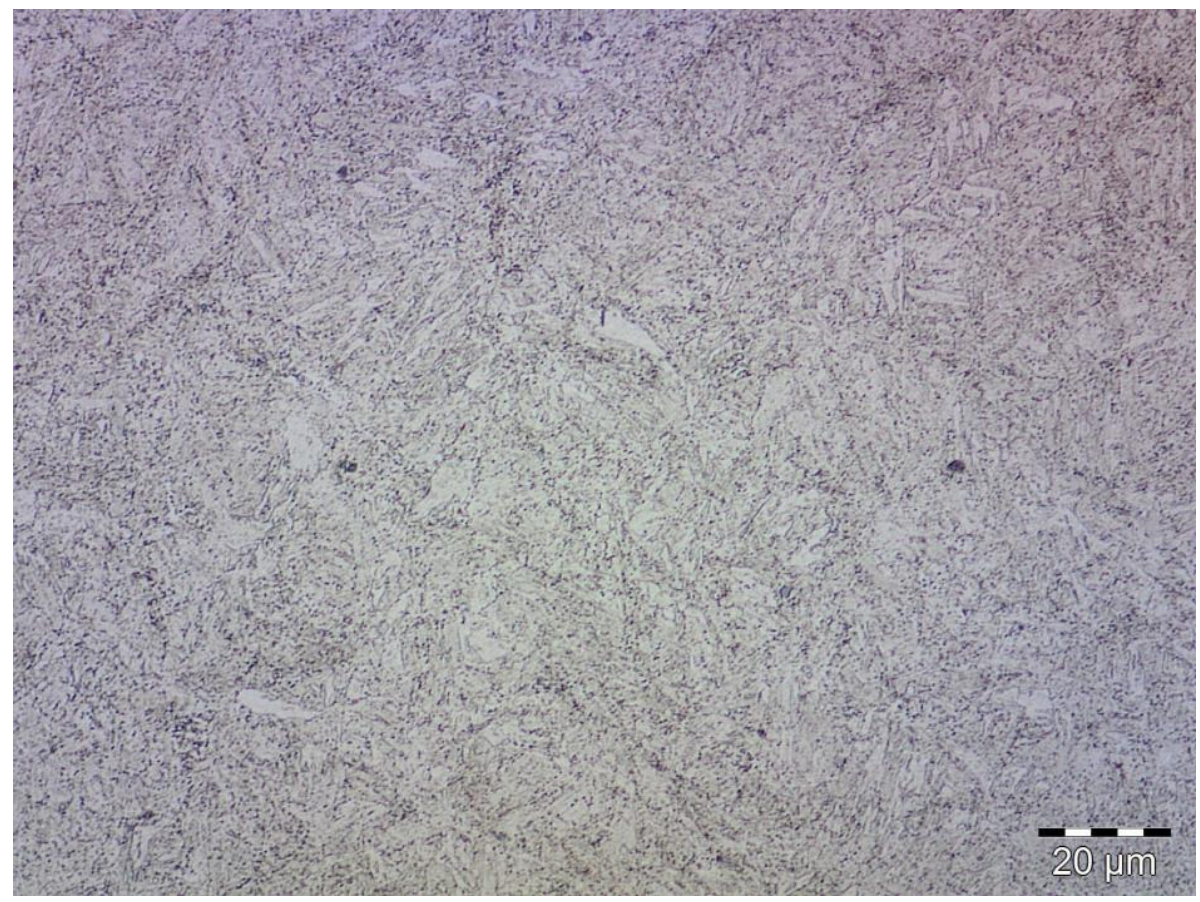

Figure 8 Parent plate microstructure of the 26 NiCrMoV14-5 steel alloy at a magnification of approximately $500 x$, the scale bar is accurate. 



Figure 9 Illustration of a test piece used to simulate FHPP on damaged blade attachment fingers. The arrow indicates the backing plate in a recess in the bottom fixture.



Figure 10 Macrograph of specimen W2, as-welded and undrilled 


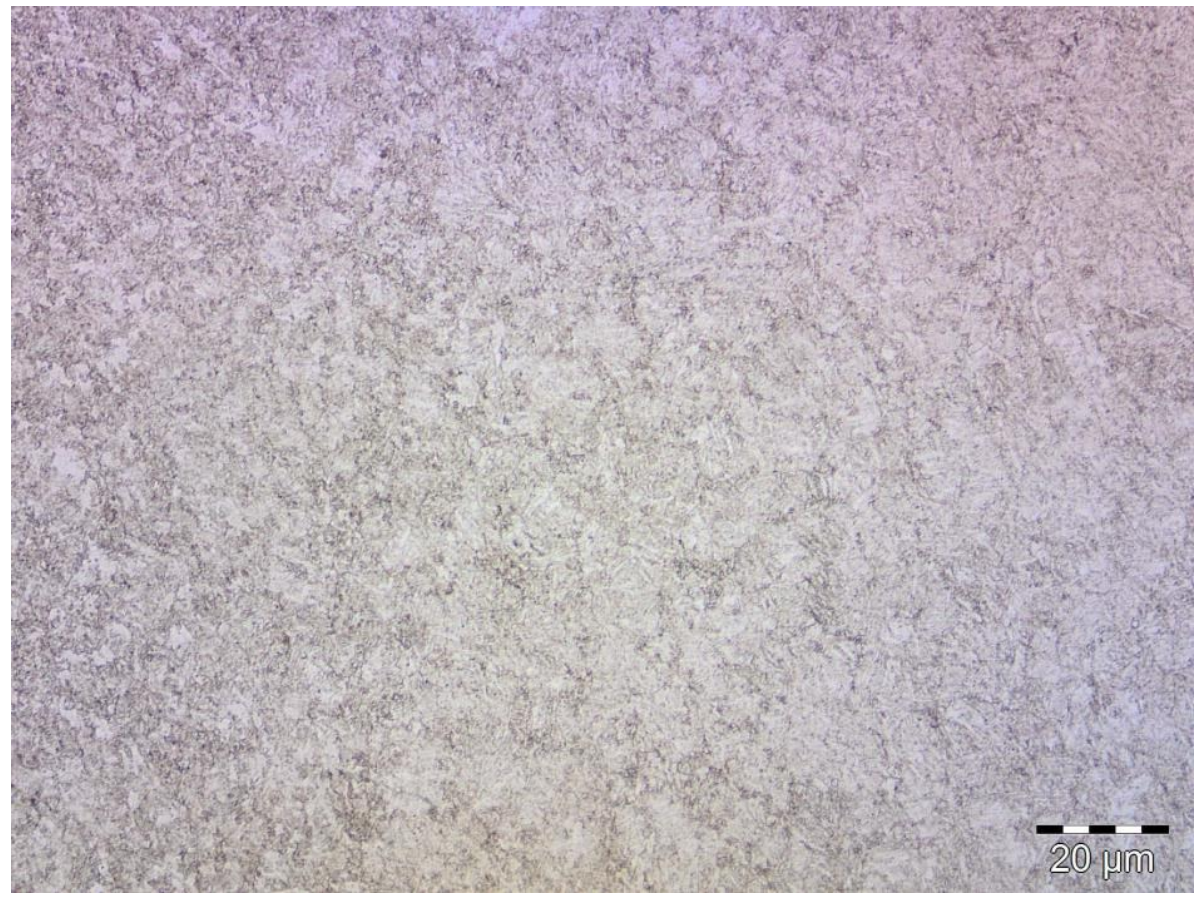

Figure 11 HAZ region in specimen W2; the microstructure is little changed from the parent plate and hardness values in the two regions would be expected to be similar.

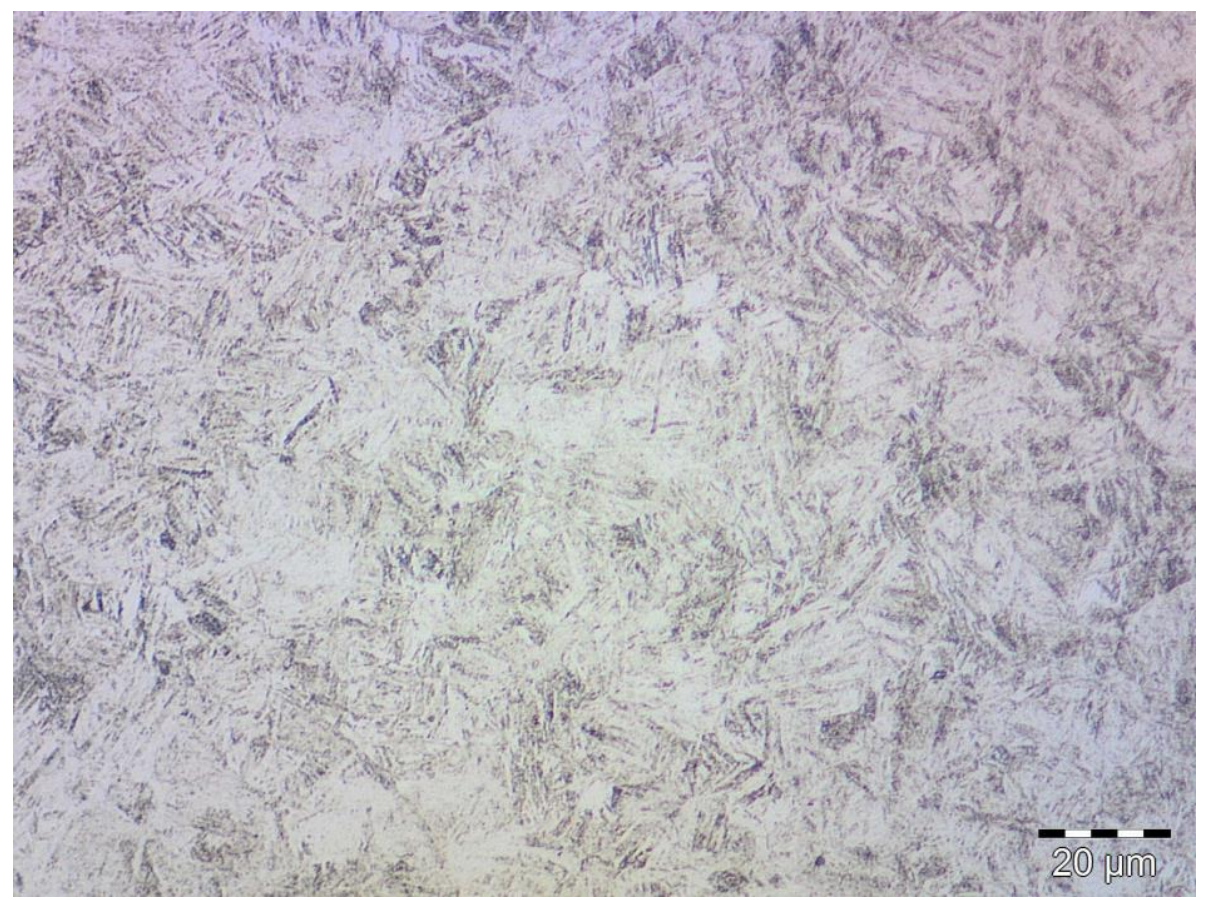

Figure 12 Tool core zone in specimen W2; the micrograph shows evidence of a fast cooling rate and hence a higher hardness than the parent plate. 


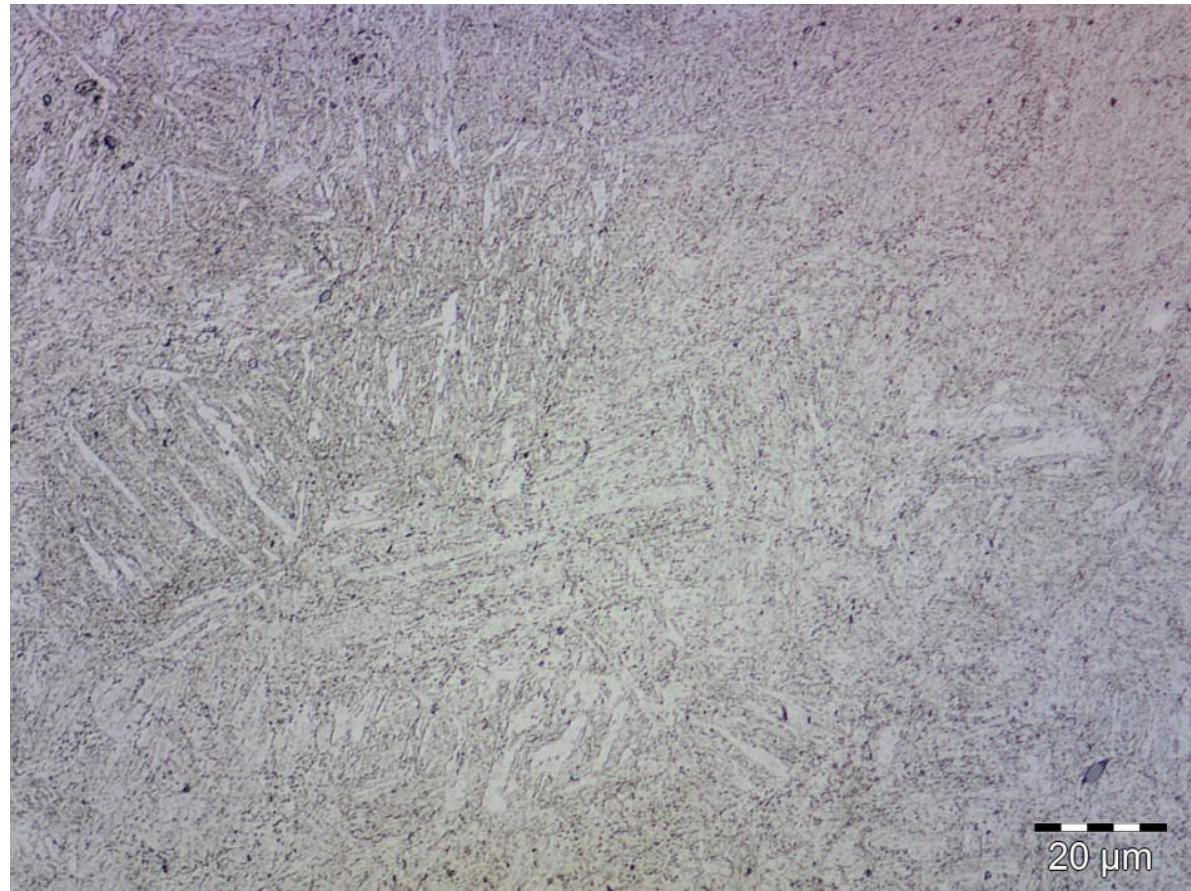

Figure 13 Tool core region in specimen $\mathrm{W} 4$ after $\mathrm{PWHT}$ at $680^{\circ} \mathrm{C}$; there is little discernible difference between this microstructure and the parent plate.

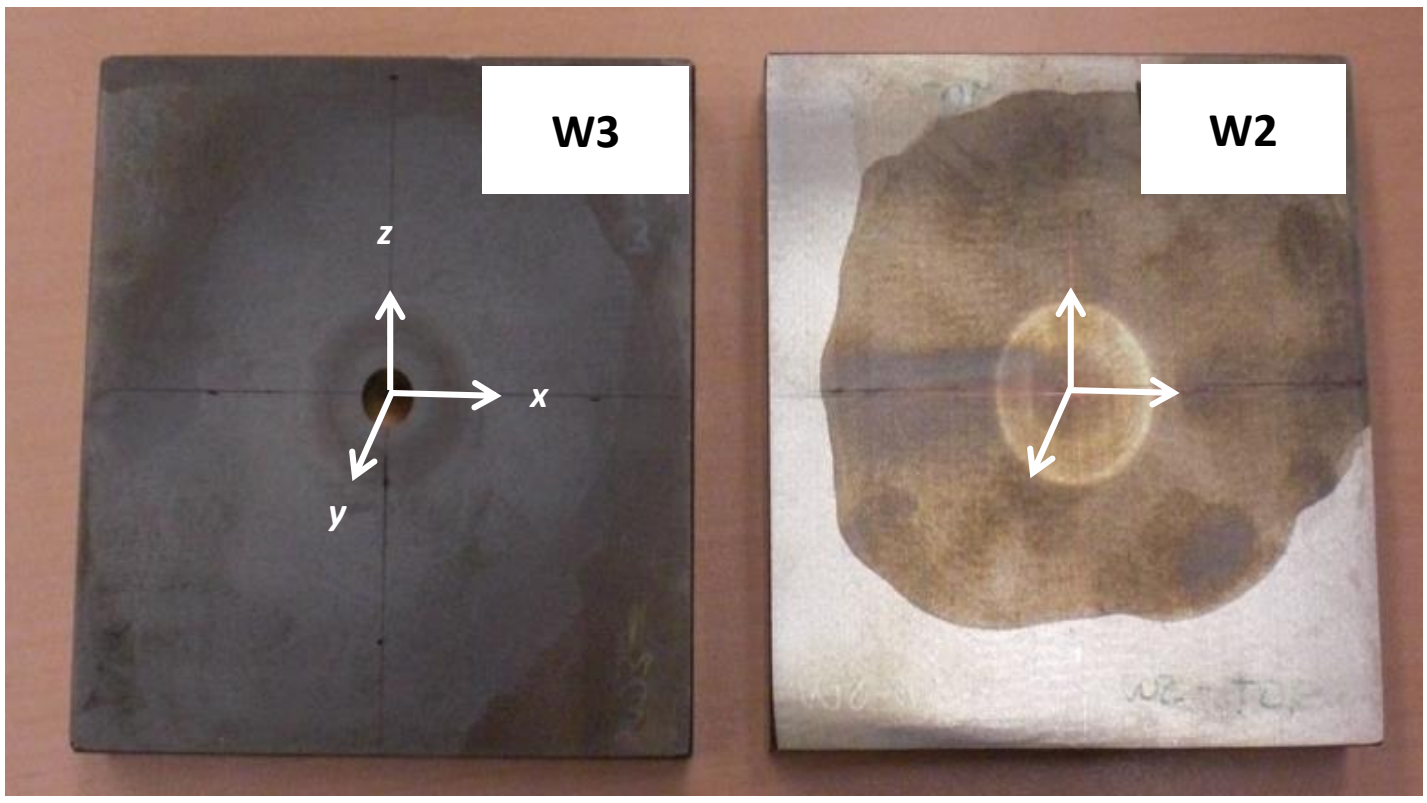

Figure $14 \quad$ Illustration of test specimens and coordinate axis directions. 


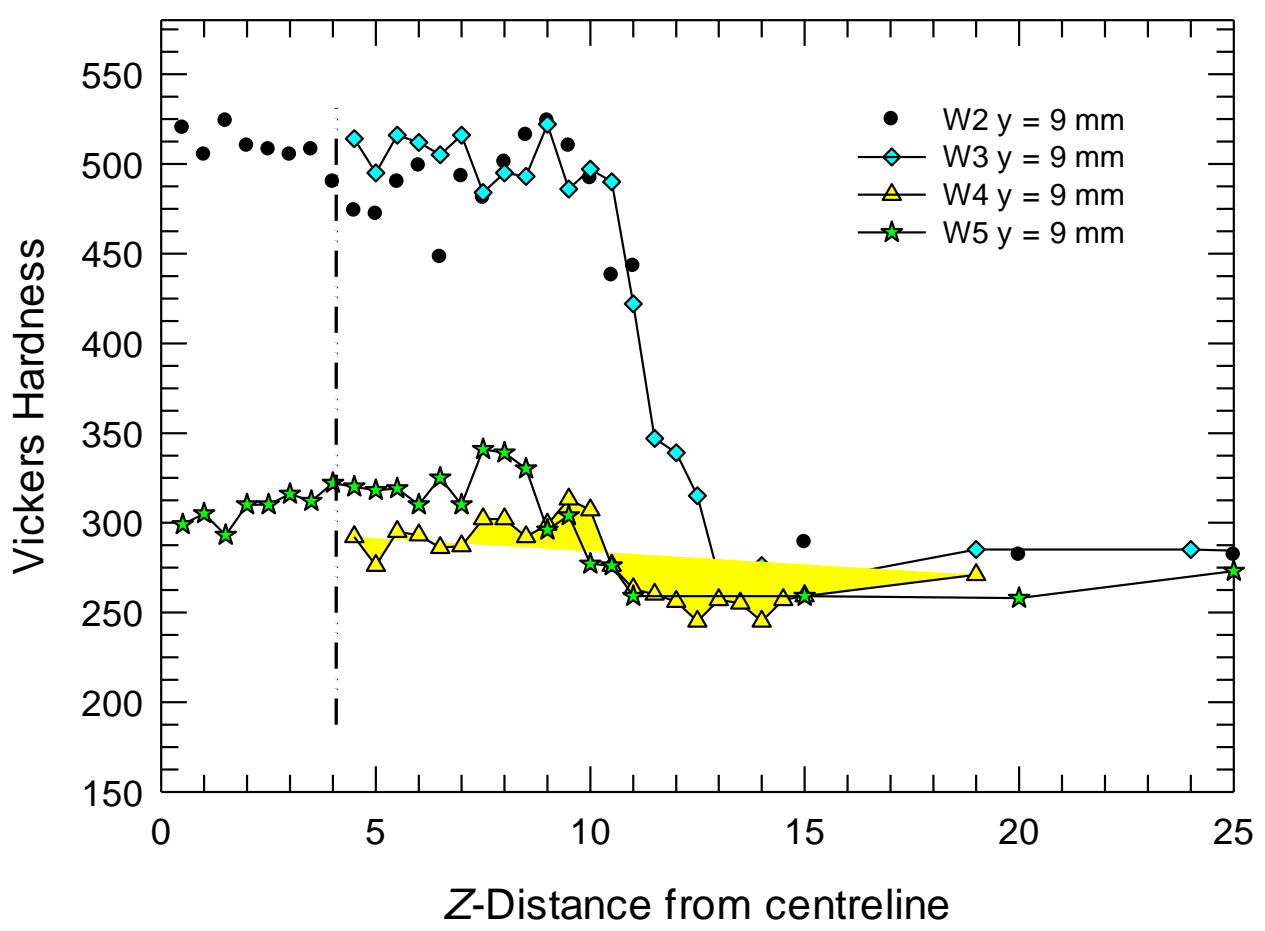

Figure 15a Vickers hardness at $9 \mathrm{~mm}$ depth for all specimens measured in the $z$ coordinate direction; the vertical dashed line represents the edge of the original hole in specimens W3 and W4.



Figure 15b Vickers hardness at $9 \mathrm{~mm}$ depth for all specimens measured in the $x$ coordinate direction; the vertical dashed line represents the edge of the original hole in specimens W3 and W4. 


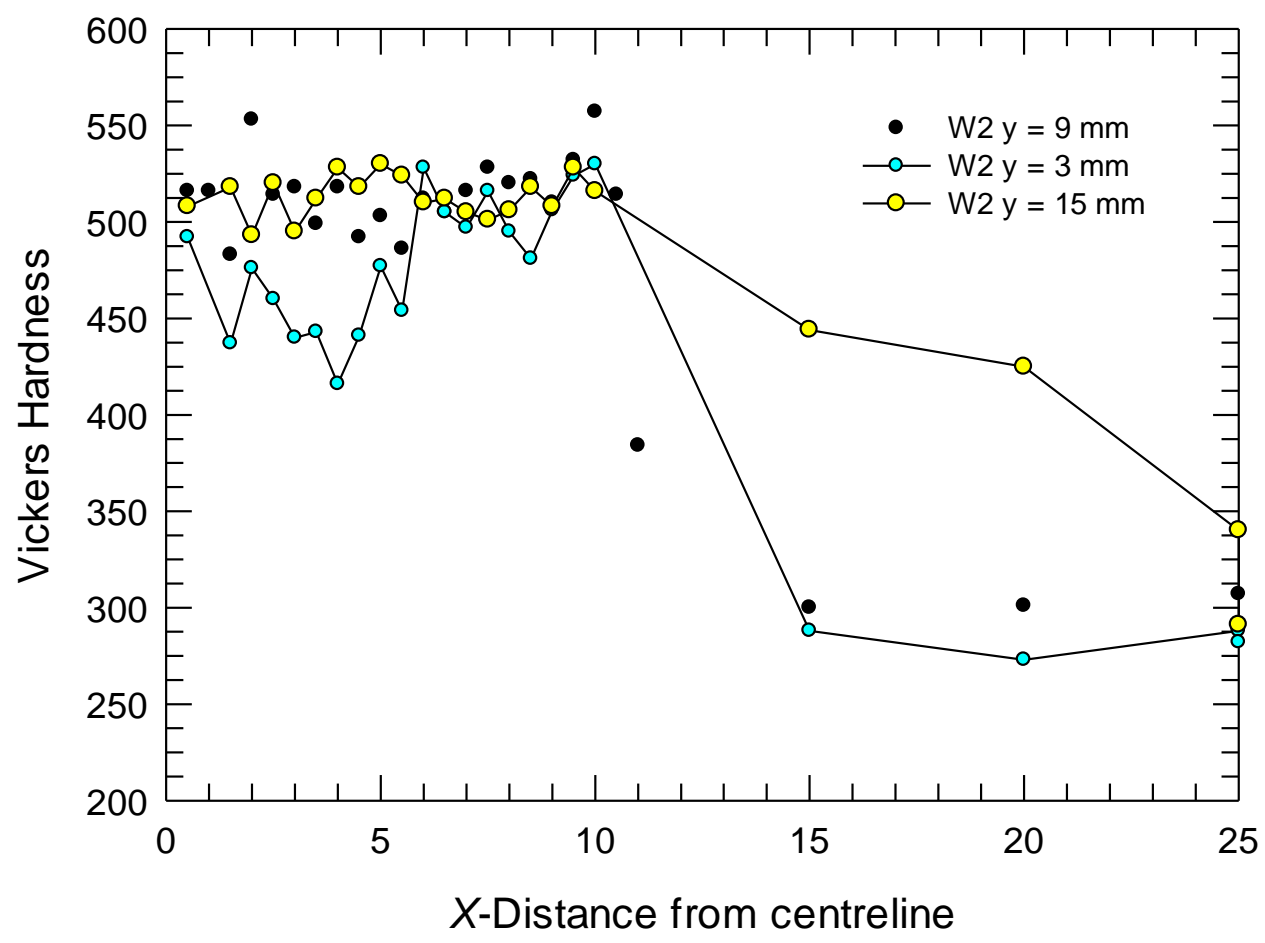

Figure 16a Vickers hardness at three depths in the as-welded W2 specimen; the hardness in the welded zone at $3 \mathrm{~mm}$ is lower, while the hardness decays more slowly outside the welded zone at the $15 \mathrm{~mm}$ depth, than observed at the other two depths. 


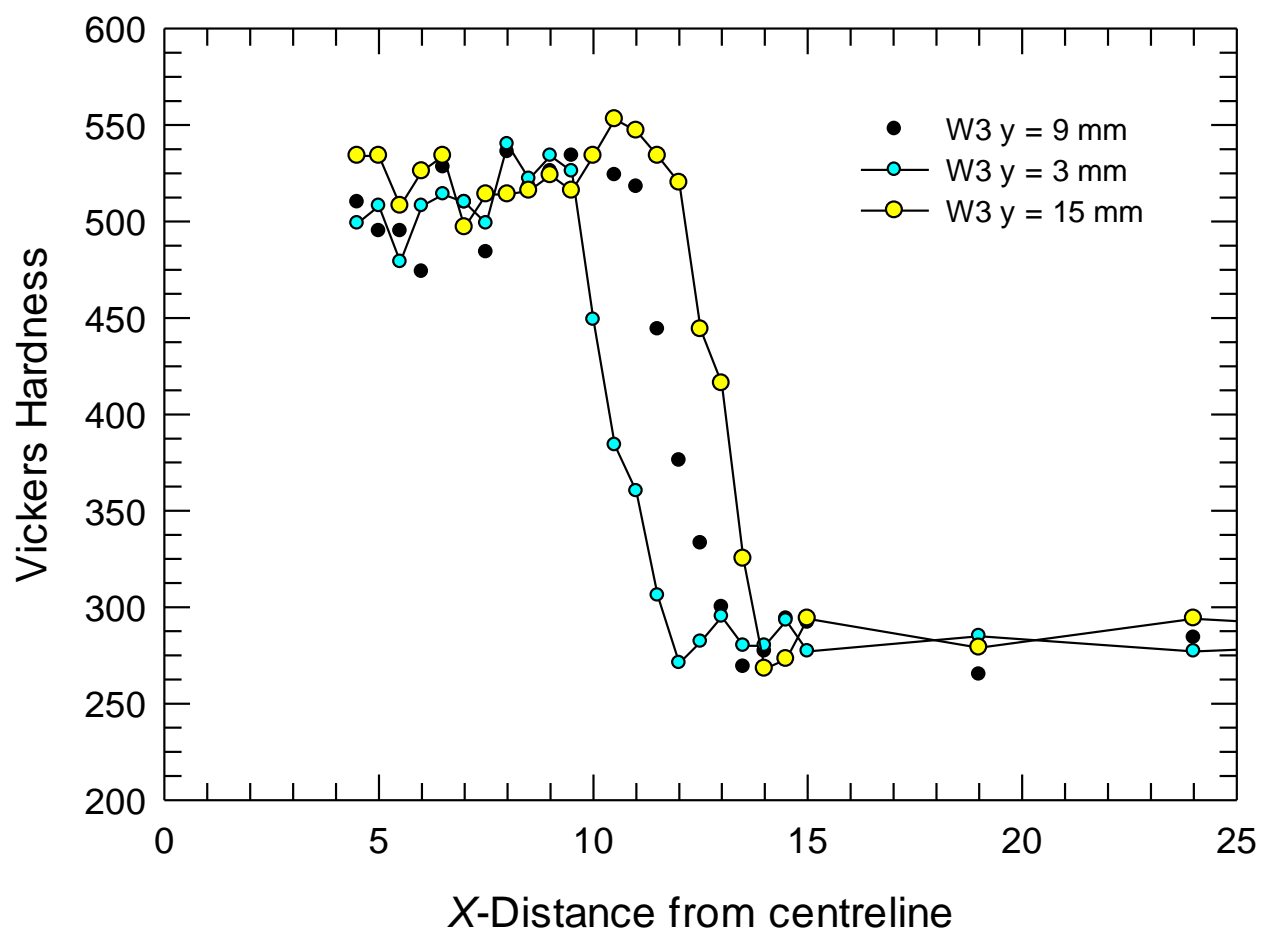

Figure 16b Vickers hardness at three depths in the as-welded W3 specimen drilled with an $8 \mathrm{~mm}$ hole; the extent of the high hardness zone gets progressively slightly larger as the depth in the specimen increases from $3 \mathrm{~mm}$ to $15 \mathrm{~mm}$. 


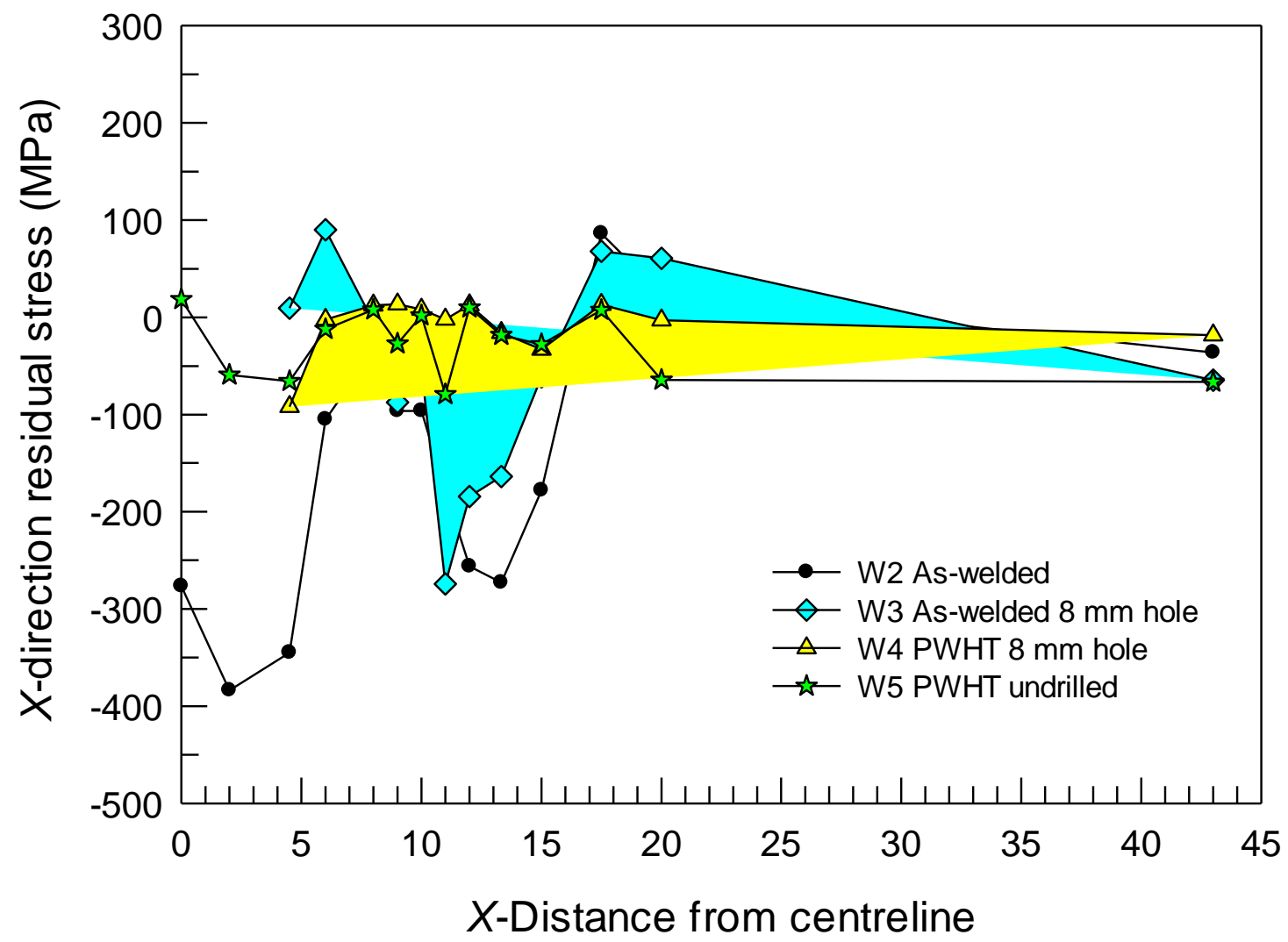

Figure 17a Mid-depth residual stress $(y=9 \mathrm{~mm})$ in the $x$-coordinate direction for all specimens. 


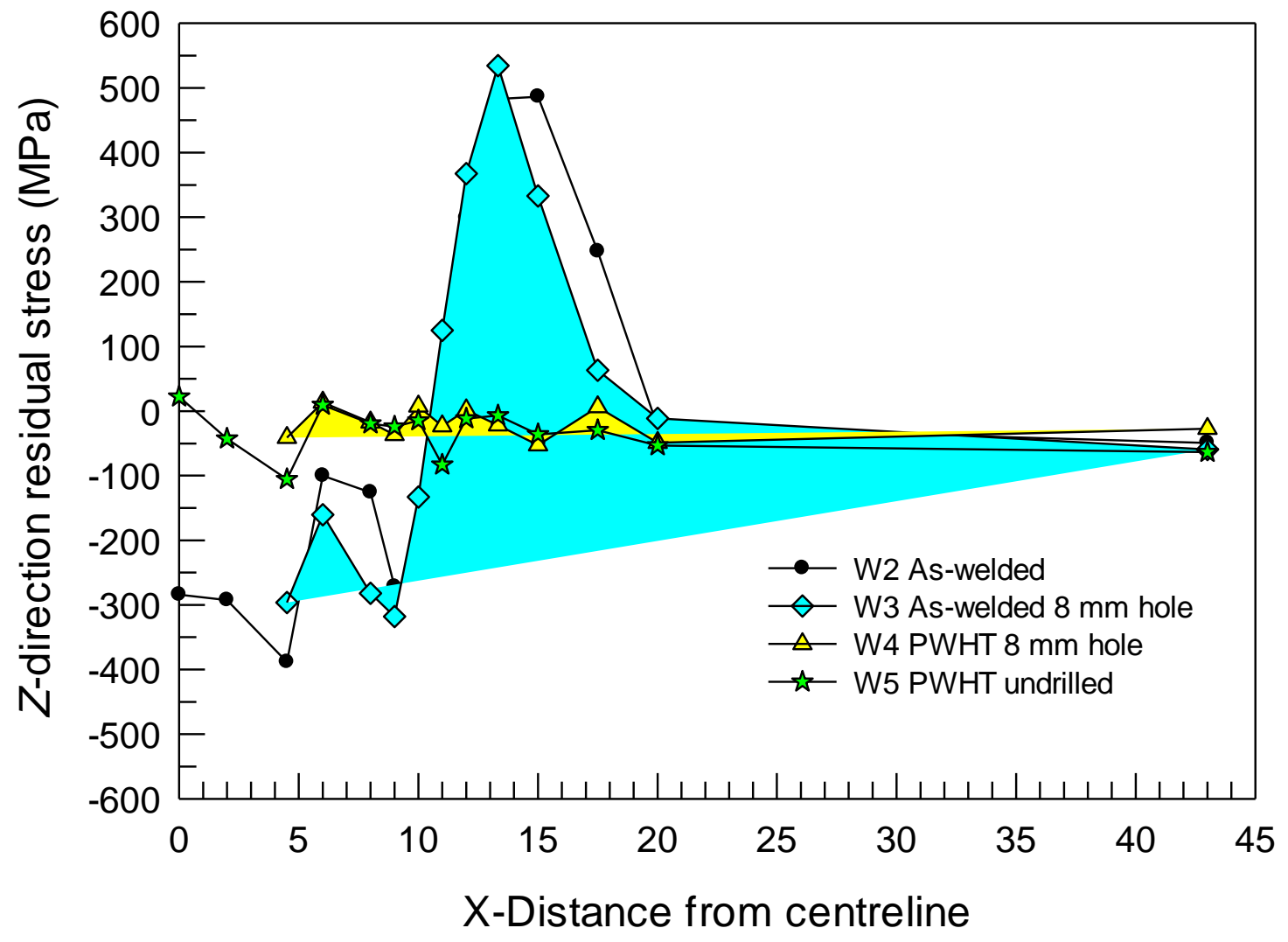

Figure 17b Mid-depth residual stress $(y=9 \mathrm{~mm})$ in the $z$-coordinate direction for all specimens. 


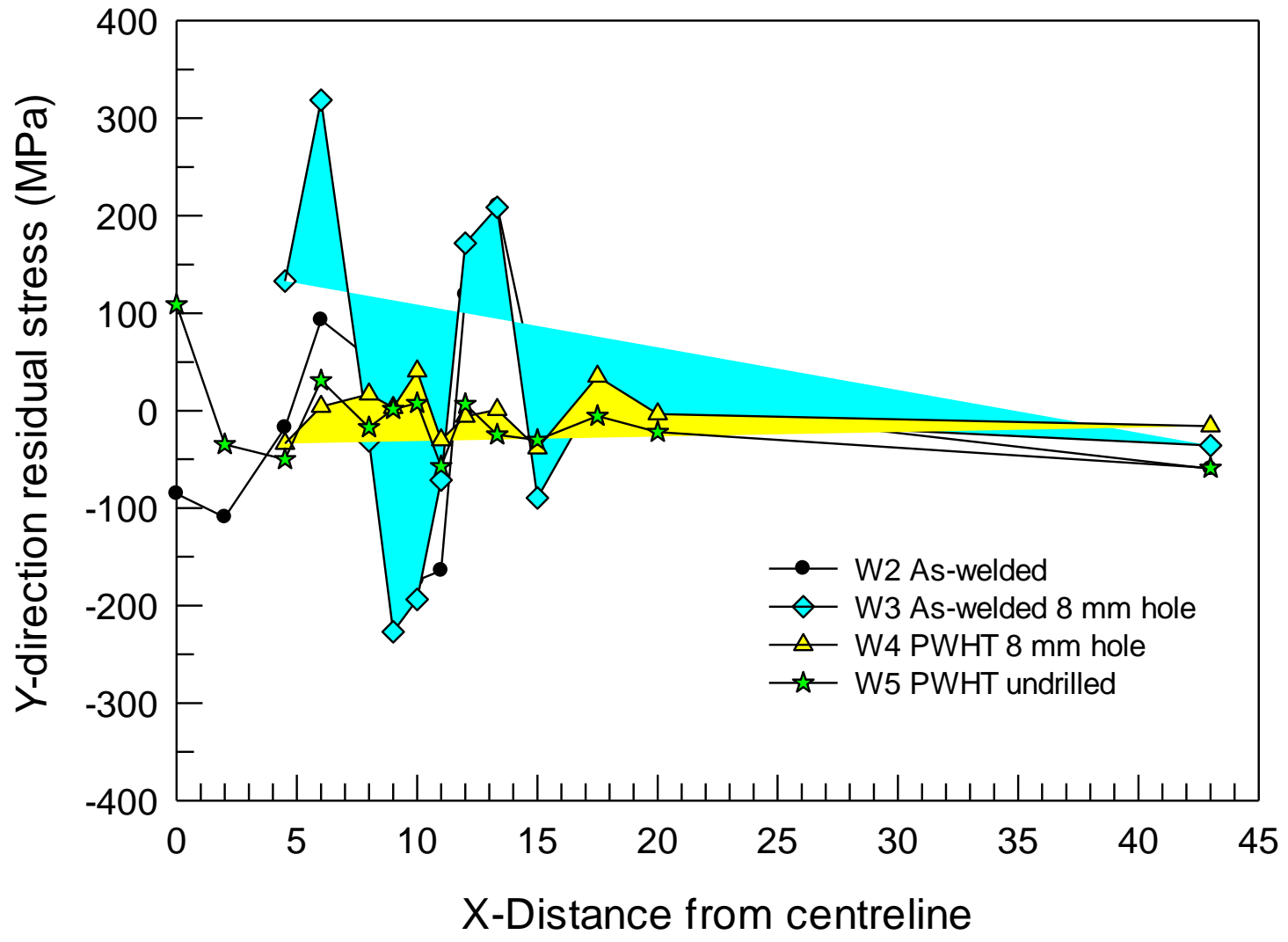

Figure 17c Mid-depth residual stress $(y=9 \mathrm{~mm})$ in the $y$-coordinate direction (throughthickness) for all specimens. 


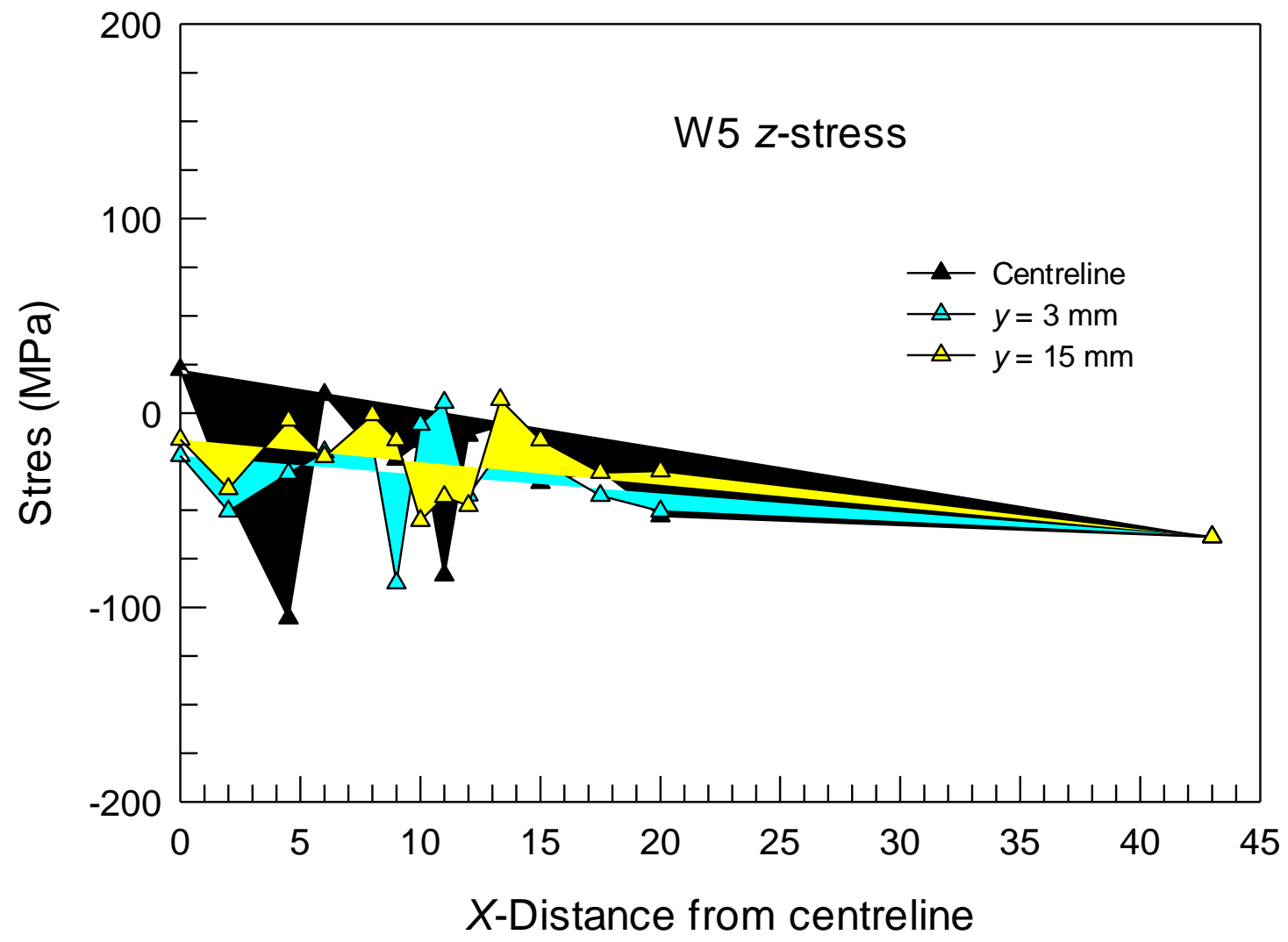

Figure 18a Stress at all three depths in the $z$-coordinate direction for the undrilled PWHT specimen W5. 


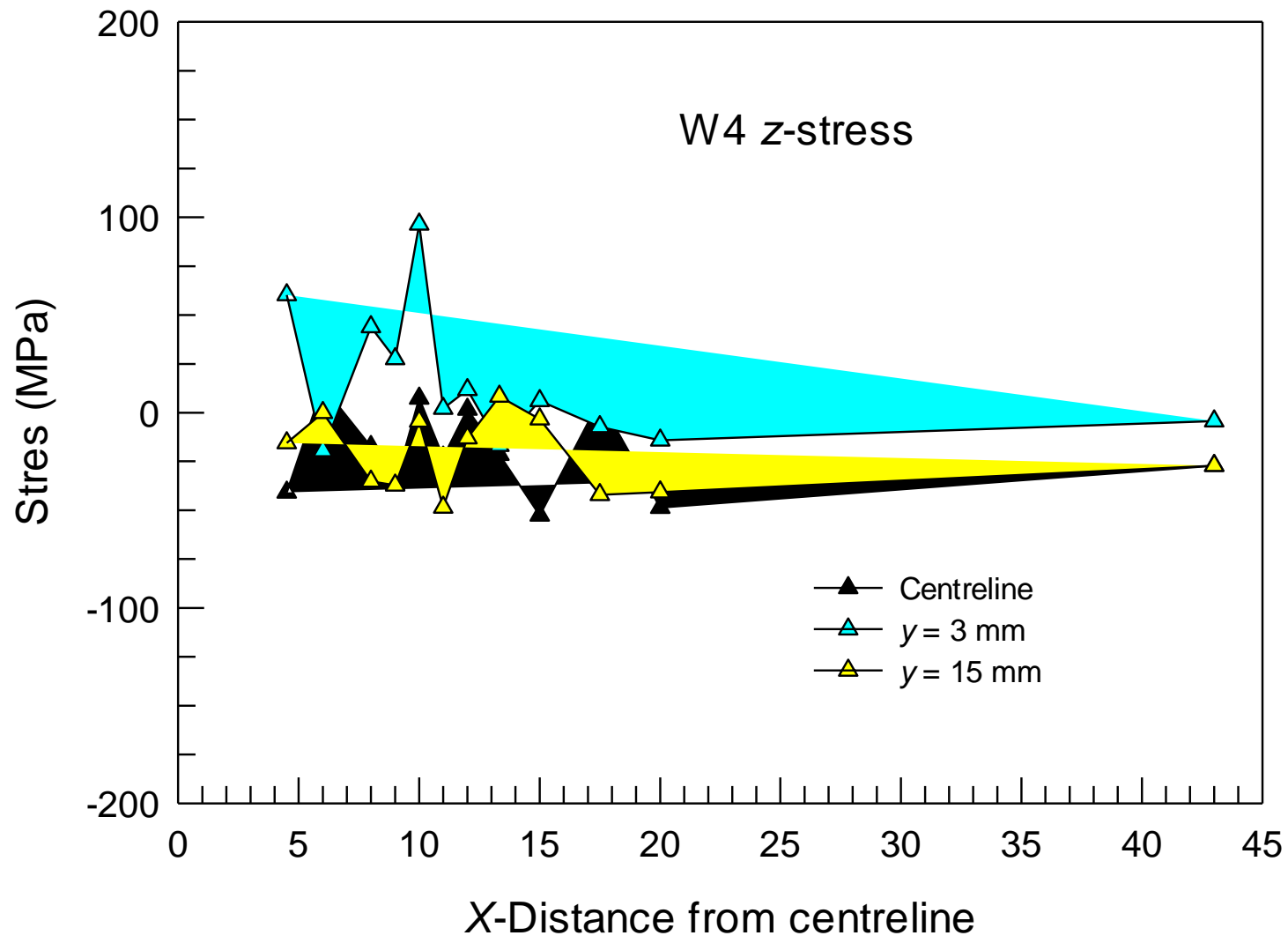

Figure 18b Stress at all three depths in the $z$-coordinate direction for the drilled PWHT specimen W4. 


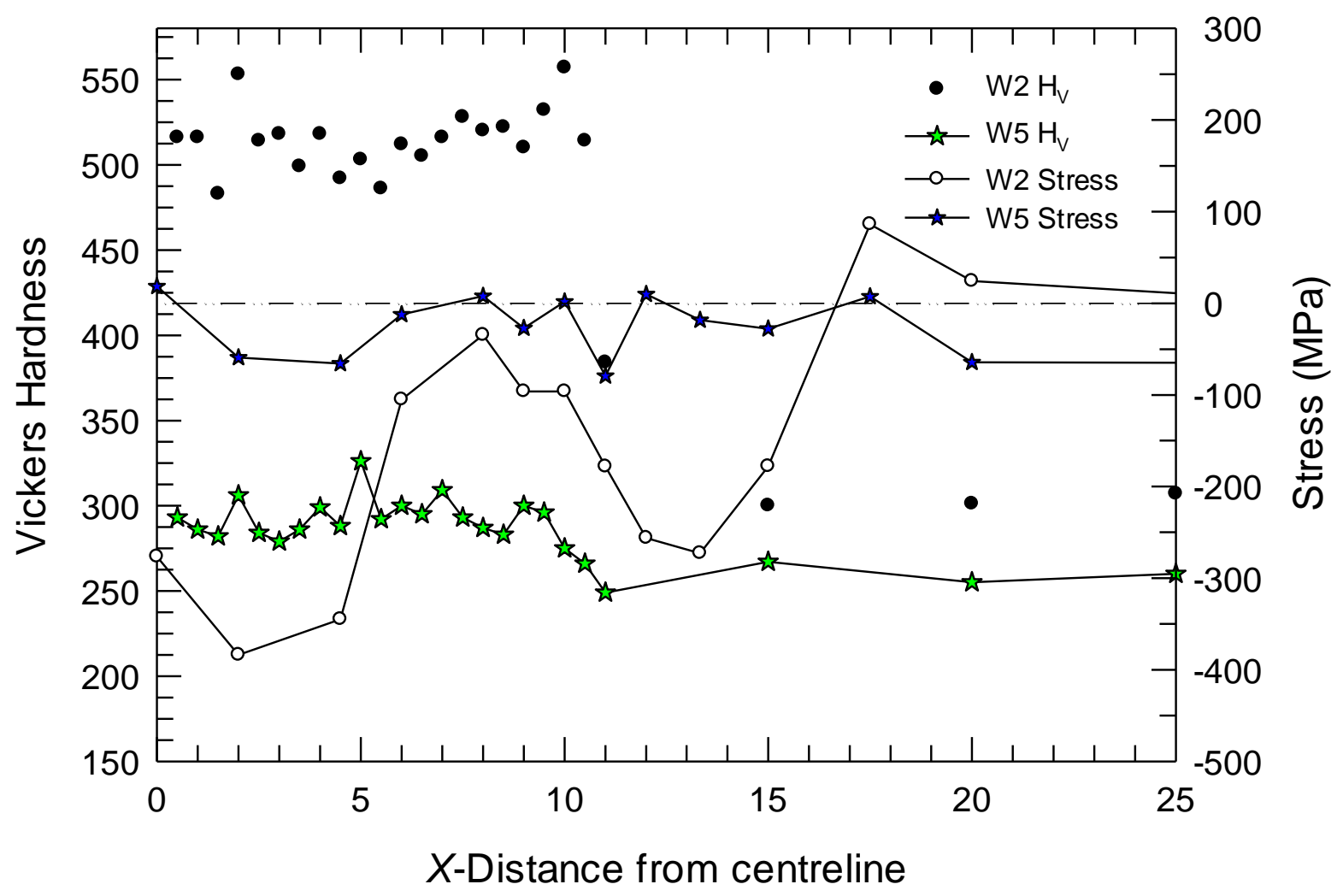

Figure 19 Comparison between mid-depth hardness and $x$-coordinate direction stress in W2 (as-welded) and W5 (undrilled PWHT). 




Figure 20 Illustration of the bespoke FHHP platform in position on a stream turbine rotor. It uses the registered WeldCore ${ }^{\circledR}$ process and in this case, is being used to extract samples for creep damage analysis. 